Available online at www.refaad.com

VMPH 1(2); 2020: 48-52

Research Article

Veterinary Medicine and Public Health Journal (VMPH)

Journal Homepage: https://www.refaad.com/views/vmph/home.aspx

www.refaad.com

ISSN : 2707-7195(Online) 2707-7187(Print)

\title{
Prevalence of Human Specific Giardia lamblia in Irish Sheltered Canines: An Unknown Risk Factor for Human Infection
}

\author{
Elizabeth R. Horgan a, Louise M. O'Connor a,b*, Rita E. Gately c, Áine B. McNamara d, Cara R. Osborne a,d, \\ Dearbháile C. Morris ${ }^{\mathrm{a}, \mathrm{b}}$
}

a Antimicrobial Resistance and Microbial Ecology Group, School of Medicine, National University of Ireland, Galway, Ireland. a,b Antimicrobial Resistance and Microbial Ecology Group, School of Medicine, National University of Ireland, Galway, Ireland, Centre for One Health, Ryan Institute, National University of Ireland, Galway, Ireland.

c Galway County Council, Galway, Ireland.

d Department of Public Health, HSE West, Galway, Ireland.

a,d Antimicrobial Resistance and Microbial Ecology Group, School of Medicine, National University of Ireland, Galway, Ireland, Department of Public Health, HSE West, Galway, Ireland.

a,b Antimicrobial Resistance and Microbial Ecology Group, School of Medicine, National University of Ireland, Galway, Ireland, Centre for One Health, Ryan Institute, National University of Ireland, Galway, Ireland.

*Corresponding Author: Louise O'Connor (louise.oconnor@nuigalway.ie)

How to cite this article: Horgan et al. Prevalence of Human Specific Giardia lamblia in Irish Sheltered Canines: An Unknown Risk Factor for Human Infection. Veterinary Medicine and Public Health Journal 1(2); 2020: 48-52.

DOI: https://doi.org/10.31559/vmph2020.1.2.4

Received Date: 18/3/2020 Accepted Date: 23/4/2020

\begin{abstract}
Giardia lamblia is a prominent cause of parasitic-induced diarrhoea with prolonged infections linked to temporary malabsorption. In 2018, 270 giardiasis cases were notified in Ireland, a six-fold increase since 2013. Although $G$. lamblia is genetically grouped into 8 host-specific assemblages, with A and B specific to human infection and $C$ and D specific to canine infection, reports of human-specific assemblages in canines are becoming more frequent. With increasing cases in Ireland and reports of zoonotic transmission potential, the aim of this study was to assess the prevalence of $G$. lamblia in Irish sheltered canines. Faecal samples were collected from two dog shelters in the west of Ireland. Real-time PCR was used to detect $G$. lamblia. Risk factors for G. lamblia colonisation were statistically analysed. Overall, 51 faecal samples were collected with a $67 \%$ prevalence of $G$. lamblia. There were $38 \%$ of dogs positive in Shelter 1 and $87 \%$ in Shelter 2 . Shelter of origin $(p=0.0006)$ and time spent in shelter $(p=0.0013)$ were significantly associated with increased $G$. lamblia prevalence, with dogs present in the shelter more than two weeks 10 times more likely to be infected with G. lamblia (Odds Ratio:10.185; Confidence Interval:2.303-45.044). This is the first Irish study to assess presence of $G$. lamblia in dogs using real-time PCR. The high prevalence among asymptomatic dogs shows their potential to contribute to human illness if correct hand-hygiene is not observed. This quantitative data is important in the implementation of effective measures to tackle giardiasis in Ireland.
\end{abstract}

\section{Keywords: Dogs; Parasite; Giardia; Transmission; Real-time PCR}

\section{Introduction}

Giardia lamblia ( $G$. lamblia) is a non-invasive parasite that attaches and replicates within the intestinal epithelium of humans and animals $[4,17]$. Both attachment and product excretion compromise the intestinal epithelia integrity and brush border enzyme function, while inducing apoptosis, leading to increased permeability and disturbed electrolyte balance. [2]. Giardiasis transmission may be waterborne, faecal-oral or foodborne [13]. As few as $10 \mathrm{G}$. lamblia cysts can cause infection, which may be asymptomatic or present with severe symptoms of watery diarrhoea, flatulence, foul smelling stools, nausea and weight loss $[2,16,10]$. Moreover, research has suggested that prolonged infection may be linked to irritable bowel syndrome and reactive arthritis [2]. Overall, giardiasis can be effectively treated using 
antibiotics such as nitazoxanide, tinidazole and metronidazole [2]. Vulnerable groups include young children, the elderly and immunocompromised individuals [11].

Annually, $G$. lamblia is responsible for approximately 280 million global infections and was named one of WHO's neglected diseases in 2004 [12]. G. lamblia is the most common water- and food-borne parasitic disease in the EU, with 19,437 giardiasis cases reported in 2017 [3]. Notifications increased six-fold between 2013 and 2018, with 270 giardiasis cases in Ireland in 2018 [8]. This increase has been attributed to the introduction of more sensitive molecular methods of detection and improved lab practices regarding stool sampling, suggesting the prevalence of giardiasis may have been previously underestimated [9]. Moreover, although once perceived to be a travel-associated infection, the majority of Irish cases in 2017 were acquired in Ireland, with only $37 \%$ cases travel-attributable [9].

$G$. lamblia can be genetically grouped into 8 host-specific assemblages. Epidemiological evidence and the maintenance of host-specific assemblages suggest human-to-human transmission is more prevalent than zoonotic transmission - with assemblages A and B specific to human-infection, assemblages $\mathrm{C}$ and $\mathrm{D}$ to canine-infection and assemblage $\mathrm{F}$ to feline-infection. However, reports of assemblage $\mathrm{A}$ and $\mathrm{B}$ in companion animals are becoming more frequent, with one study in Bangkok reporting $76 \%$ of dogs carried assemblage $A$ and $21 \%$ carried assemblage B [20].

Thus, with increasing reports of giardiasis in Ireland and zoonotic transmission potential, the prevalence of $G$. lamblia among Irish canines needs to be elucidated to assess their contribution to giardiasis persistence and potential for human risk.

\section{Methods}

\section{Faecal Sample Collection}

In June 2019, 51 faecal samples were collected from two dog shelters in the west of Ireland. Samples were transferred into sterile tubes straight after defecation. Where possible, details on individual canine species, breed, gender, age, origin, length of time in shelter, current medication and presence of diarrhoea were recorded. Faeces were transported to the lab within $5 \mathrm{~h}$ of sample collection under low temperature, and subsequently stored at $4^{\circ} \mathrm{C}$. Samples were analysed within 5 days of sampling, before being frozen at $-20^{\circ} \mathrm{C}$ for downstream processing.

\section{Giardia lamblia Detection}

DNA was extracted from each faecal sample using the QIAamp PowerFecal DNA Kit (Qiagen UK) and stored at $-80^{\circ} \mathrm{C}$, as per manufacturer guidelines. Real-time PCR analysis on extracted DNA was carried out using Assay B of the Gastro Panel 2 Kit (Serosep Ireland), as per manufacturer instructions. This assay simultaneously detects $G$. lamblia assemblage A and B, Cryptosporidium and Verotoxigenic Escherichia coli (VTEC).

\section{Statistical Analysis}

Relationships between the risk factors and $G$. lamblia detection were statistically analysed using Pearson's Chi-Squared test and Fisher's exact test, with significance levels set at $p \leq 0.05$. Risk factors (origin, gender, age and category i.e. surrender or stray) were chosen which could be measured and which may reasonably be considered to impact on colonisation of canines with $G$. lamblia. Additionally, odds ratios (OR) and 95\% confidence intervals (CI) were calculated using $2 \mathrm{X} 2$ contingency tables. Statistical analysis was performed using Excel and an online resource (http://vassarstats.net/) for statistical computation.

\section{Results Study Cohort}

Overall, a total of 51 canine faecal samples were collected between Shelter 1 (21/51) and Shelter 2 $(30 / 51)$. Samples were collected from both male (51\%) and female (49\%) dogs, stratified into three age groups: $\leq 1$ years old (39\%), $>1$ year old (53\%) and unknown (8\%). The majority of dogs were stray (65\%), with the remainder surrenders (35\%). Time spent in the shelter was categorized into four groups: $<1$ week (19.5\%), 1-2 weeks (19.5\%), >2 weeks (55\%) and unknown (6\%). All faecal samples collected were diarrhoea asymptomatic (100\%).

\section{Prevalence of $G$. lamblia}

The prevalence of $G$. lamblia infection was $67 \%$, with $38 \%$ of dogs positive in Shelter 1 and $87 \%$ positive in Shelter 2. No samples displayed infection or co-infection with Cryptosporidium or VTEC. When age, gender and animal origin were considered, the prevalence was: $69 \%$ among males and 64\% among females; $70 \%$ in $\leq 1$ year/old and $67 \%$ in $>1$ year/olds; $67 \%$ in both surrender and stray dogs. Prevalence was $20 \%$ in dogs in the shelter $<1$ week, $70 \%$ in dogs present $1-2$ weeks and $89 \%$ in dogs present $>2$ weeks (Table 1 ). 
Table (1): Prevalence of G. lamblia in Sheltered Canines Examined According to Origin, Gender, Age, Animal Category, Time in Shelter and Diarrhoea

\begin{tabular}{|c|c|c|c|c|c|c|c|c|c|c|}
\hline \multirow[b]{2}{*}{ Factor } & \multirow[b]{2}{*}{ Group } & \multicolumn{3}{|c|}{ Shelter $1(n=21)$} & \multicolumn{3}{|c|}{ Shelter $2(n=30)$} & \multicolumn{3}{|c|}{ Total $(n=51)$} \\
\hline & & $\begin{array}{c}\text { Total } \\
n\end{array}$ & $\begin{array}{c}\text { Positive } \\
n\end{array}$ & $\begin{array}{c}\text { Prevalence } \\
(\%)\end{array}$ & $\begin{array}{c}\text { Total } \\
n\end{array}$ & $\begin{array}{c}\text { Positive } \\
n\end{array}$ & $\begin{array}{c}\text { Prevalence } \\
(\%)\end{array}$ & Total $n$ & $\begin{array}{c}\text { Positive } \\
n\end{array}$ & $\begin{array}{c}\text { Prevalence } \\
(\%)\end{array}$ \\
\hline \multirow[t]{2}{*}{ Origin } & Shelter 1 & & & & & & & 21 & 8 & $38 \%$ \\
\hline & Shelter 2 & & & & & & & 30 & 26 & $87 \%$ \\
\hline \multirow[t]{2}{*}{ Gender } & Male & 12 & 5 & $42 \%$ & 14 & 13 & $93 \%$ & 26 & 18 & $69 \%$ \\
\hline & Female & 9 & 3 & $33 \%$ & 16 & 13 & $81 \%$ & 25 & 16 & $64 \%$ \\
\hline \multirow[t]{3}{*}{ Age } & $\leq 1$ year/old & 6 & 2 & $33 \%$ & 14 & 12 & $86 \%$ & 20 & 14 & $70 \%$ \\
\hline & $>1$ year old & 11 & 4 & $36 \%$ & 16 & 14 & $88 \%$ & 27 & 18 & $67 \%$ \\
\hline & Unknown & 4 & 2 & $50 \%$ & 0 & 0 & $0 \%$ & 4 & 2 & $50 \%$ \\
\hline \multirow[t]{2}{*}{ Category } & Surrender & 10 & 5 & $50 \%$ & 8 & 7 & $88 \%$ & 18 & 12 & $67 \%$ \\
\hline & Stray & 11 & 3 & $27 \%$ & 22 & 19 & $86 \%$ & 33 & 22 & $67 \%$ \\
\hline \multirow{4}{*}{$\begin{array}{l}\text { Time in } \\
\text { Shelter }\end{array}$} & $<1$ week & 8 & 2 & $25 \%$ & 2 & 0 & $0 \%$ & 10 & 2 & $20 \%$ \\
\hline & 1-2 weeks & 4 & 2 & $50 \%$ & 6 & 5 & $83 \%$ & 10 & 7 & $70 \%$ \\
\hline & $>2$ weeks & 6 & 4 & $67 \%$ & 22 & 21 & $95 \%$ & 28 & 25 & $89 \%$ \\
\hline & Unknown & 3 & 0 & $0 \%$ & 0 & 0 & $0 \%$ & 3 & 0 & $0 \%$ \\
\hline
\end{tabular}

No significant association was found between $G$. lamblia prevalence and gender $(p=0.6892)$, age $(p=0.8065)$ or animal category $(p=1.0000)$. Shelter of origin was found to be highly associated with increased $G$. lamblia prevalence, with a significantly higher prevalence in Shelter $2(p=0.0006)$. Dogs in Shelter 2 were more than 10 times more likely to carry G. lamblia (OR:10.56; CI:2.667-41.673). Similarly, the amount of time dogs spent in the shelter significantly increased the prevalence of $G$. lamblia ( $p=0.0013)$, where dogs who stayed greater than 2 weeks in the shelter were 10 times more likely to carry G. lamblia (OR:10.185; CI:2.303-45.044) (Table 2).

Table (2): Risk Factors for G. lamblia Infection in Sheltered Canines obtained by Statistical Analysis

\begin{tabular}{|c|c|c|c|c|c|}
\hline $\begin{array}{c}\text { Risk } \\
\text { Factor }\end{array}$ & Group & $\begin{array}{c}\text { Prevalence } \\
(\%)\end{array}$ & OR & $\begin{array}{c}95 \% \\
\text { CI } \\
\end{array}$ & $\begin{array}{c}\mathrm{P} \\
\text { Value }\end{array}$ \\
\hline \multirow[t]{2}{*}{ Origin } & Shelter 2 & $87 \%$ & 10.56 & $\begin{array}{r}2.667 \\
41.673 \\
\end{array}$ & 0.0006 \\
\hline & Shelter 1 & $38 \%$ & 1.00 & & \\
\hline \multirow[t]{2}{*}{ Gender } & Male & $69 \%$ & 1.27 & $\begin{array}{l}0.394 \\
4.063 \\
\end{array}$ & 0.6892 \\
\hline & Female & $64 \%$ & 1.00 & & \\
\hline \multirow[t]{2}{*}{ Age } & $\begin{array}{c}\leq 1 \\
\text { year/old }\end{array}$ & $70 \%$ & 1.17 & $\begin{array}{l}0.335 \\
4.060\end{array}$ & 0.8065 \\
\hline & $\begin{array}{c}>1 \text { year } \\
\text { old }\end{array}$ & $67 \%$ & 1.00 & & \\
\hline \multirow[t]{2}{*}{ Category } & Surrender & $67 \%$ & 1.00 & $\begin{array}{l}0.296 \\
3.381\end{array}$ & 1 \\
\hline & Stray & $67 \%$ & 1.00 & & \\
\hline \multirow[t]{2}{*}{$\begin{array}{l}\text { Time in } \\
\text { Shelter }\end{array}$} & $\begin{array}{c}>2 \\
\text { weeks }\end{array}$ & $89 \%$ & 10.19 & $\begin{array}{r}2.303 \\
45.044 \\
\end{array}$ & 0.0013 \\
\hline & $0-2$ weeks & $45 \%$ & 1.00 & & \\
\hline
\end{tabular}

\section{Discussion}

This study revealed $G$. lamblia to be prevalent in $67 \%$ of Irish sheltered dogs examined. Comparisons to previous Giardia prevalence reports are limited, as canine origin, detection method and assemblages detected vary substantially between studies.
However, previous global prevalence studies have been summarised by a meta-analysis study conducted by Bouzid et al. (2015), which analysed 127 separate studies and found, on average, $15.2 \%$ of canine faecal samples to be Giardia-positive [1]. With regards to Irish canines, the first $G$. lamblia prevalence report was published in 2019 [5]. This study reported $17.18 \%$ of Irish stray dogs tested positive for all G. lamblia assemblages when an ELISA coproantigen assessment was employed $(n=163)$ [5]. As samples were assessed from strays as they entered a dog shelter, the low prevalence reflects the lower prevalence in our study found in sheltered dogs present for less than 1 week $(20 \%)$.

In sheltered Irish canines, no association was found between $G$. lamblia prevalence and gender, similar to findings of previous studies $[18,22]$. Likewise, there was no significant association found between prevalence and age or animal category (stray/surrender). This was inconsistent with the previous studies that have found significantly higher prevalence among younger animals $[18,14]$ and in surrendered dogs [7,21]. There was significant association between infection and both shelter identity $(p=0.0006)$ and time in the shelter $(p=0.0013)$. However, shelter 2 had a significantly higher infection rate and a larger number of dogs present for longer, and thus, may have biased results. With regards to shelter management, the higher prevalence of $G$ lamblia in shelter 2 may have been attributable to its water supply - a private untreated well, in contrast to the public water supply at shelter 1 , subject to both UV treatment and chlorination.

It is worth noting that there are some limitations associated with the real-time PCR assay used in the study. The manufacturers in-silico sequence analysis indicated the possibility of the test detecting assemblages C, D, E and F. Given the increase in human cases, this highlights the need for development of specific diagnostic tests for the various relevant Giardia assemblages. 
Despite this, the high prevalence of $G$. lamblia found in asymptomatic dogs suggests that they may present a key source of persistence within the environment. This highlights the need to raise awareness amongst dog owners of the dangers of dog fouling and importance of good hand hygiene practices for controlling giardiasis in Ireland. As previous research suggest Giardia transmission may be influenced by previous veterinary care, living condition and situational stress $[19,6]$, a future study assessing the faecal carriage rate of Giardia assemblage A and B among household canines would allow for greater conclusions to be drawn of true risk posed to humans.

\section{Conclusion}

This is the first Irish study to investigate the presence of $G$. lamblia in sheltered dogs using realtime PCR. The high prevalence observed among asymptomatic dogs demonstrates the potential of dogs to contribute to human G. lamblia infection and highlights the need for owners to observe correct hand-hygiene practices when caring for animals. The quantitative data described here will form an important element in the implementation of effective measures to tackle giardiasis in Irish sheltered accommodation.

Acknowledgements: The authors would like to acknowledge the input and scientific guidance of Serosep Ltd. in this study.

Funding: No funding to declare

Conflict of Interest: The authors declare that there is no conflict of interest

\section{References}

[1] Bouzid. M, Halai. K, Jeffreys. D. \& Hunter. PR. The prevalence of Giardia infection in dogs and cats, a systematic review and meta-analysis of prevalence studies from stool samples. Vet Parasitol. 14(207) (2015), 181-202. doi.org/10.1016/j.vetpar.2014.12.011

[2] Centers for Disease Control and Prevention. $C D C$ Yellow Book: Health Information for International Travel p 213-214. https://wwwnc.cdc.gov/travel/yellowbook/20 20/travel-related-infectious-

diseases/giardiasis

[3] European Centre for Disease Prevention and Control. Giardiasis (lambliasis). In: Ecdc. Annual Epidemiological Report for 2017. Stockholm. https://ecdc.europa.eu/sites/portal/files/docu ments/AER_for_2017-giardiasis-lambliasis.pdf

[4] Feng. Y. \& Xiao. L. Zoonotic potential and molecular epidemiology of Giardia species and giardiasis. Clin Microbiol Rev, 24(1) (2011),110-40, doi:10.1128/CMR.00033-10

[5] Garcia-Campos. A, Power. C, O'Shaughnessy. J, Browne. C, Lawlor. A, McCarthy. G, et al. One- year parasitological screening of stray dogs and cats in County Dublin, Ireland. Parasitology. 146(6) (2019), 746-52. doi.org/10.1017/S0031182018002020

[6] Gates. MC. \& Nolan. TJ. Endoparasite prevalence and recurrence across different age groups of dogs and cats. Vet Parasitol. 166(1-2) (2009):153-158, doi:10.1016/j.vetpar2009.07.041

[7] Gil. H, Cano. L, de Lucio. A, Bailo. B, de Mingo. MH, Cardona. GA, et al. Detection and molecular diversity of Giardia duodenalis and Cryptosporidium spp. in sheltered dogs and cats in Northern Spain. Infect Genet Evol, 50(2017), 62-69, doi.org/10.1016/j.meegid.2017.02.013

[8] Health Protection Surveillance Centre. Giardiasis Available from: https://www.hpsc.ie/a$\mathrm{z} /$ gastroenteric/giardiasis/

[9] Health Protection Surveillance Centre. Giardiases in Ireland, 2017. Dublin: HSE HPSC. (2018). $\quad$ www.hpsc.ie/az/gastroenteric/giardiasis/publications/annual reports/Giardia 2017 annual report FINAL.pdf

[10] Horton. B, Bridle. H, Alexander. CL. \& Katzer. F. Giardia duodenalis in the UK: current knowledge of risk factors and public health implications. Parasitology 146(4) (2018), 413-424, doi:10.1017/S0031182018001683

[11] Jacob. P, Henry. A, Meheut. G, Charni-BenTabassi. N, Ingrand. V. \& Helmi K. Health. Risk Assessment Related to Waterborne Pathogens from the River to the Tap. Int J Environ Res Public Health. 12(3) (2015), 2967-83 doi:10.3390/ijerph120302967

[12] Kotloff. KL, Nataro. JP, Blackwelder. WC, Nasrin. D, Farag. TH, Panchalingam. S, et al. Burden and aetiology of diarrhoeal disease in infants and young children in developing countries (the Global Enteric Multicenter Study, GEMS): A prospective, case-control study. Lancet. 382(9888) (2013), 209-222 doi.org/10.1016/S0140-6736(13)60844-2

[13] Minetti. C, Lamden. K, Durband. C, Cheesbrough. J, Platt. K, Charlett. A, et al. Case-Control Study of Risk Factors for Sporadic Giardiasis and Parasite Assemblages in North West England. Gilligan PH, editor. J Clin Microbiol 53(10) (2015), 3133-40, doi:10.1128/JCM.00715-15

[14] Nguyen. ST, Fukuda. Y, Nguyen. DT, Dao. HT, LE DQ.Bui KL, et al. Prevalence, genotyping and risk factors of Giardia duodenalis from dogs in Vietnam. J Vet Med Sci. 80(1) (2018), 92-97, doi/10.1292/jvms.17-0498

[15] Ortuño, A, Scorza, V, Castellà, J. \& Lappin, M. Prevalence of intestinal parasites in shelter and hunting dogs in Catalonia, Northeastern Spain. Vet J. 199(3) (2014), 465, doi.org/10.1016/j.tvjl.2013.11.022

[16] Rendtorff. RC. The experimental transmission of human intestinal protozoan parasites. II. Giardia lamblia cysts given in capsules. Am J Hyg. 59(2) (1954), 209-20, doi:10.1093/oxfordjournals.aje.a119634

[17] Ryan. U. \& Cacciò. SM. Zoonotic potential of Giardia. Int J Parasitol. 43(12-13) (2013), 94356, doi:10.1016/j.ijpara.2013.06.001. 
[18] Scaramozzino. P, Di Cave. D, Berrilli. F, D’Orazi. C, Spaziani. A. \& Mazzanti. S, et al. A study of the prevalence and genotypes of Giardia duodenalis infecting kennelled dogs. Vet J. 182(2) (2009), 231-4. 10.1016/j.tvjl.2008.07.003

[19] Tangtrongsup. S. \& Scorza. V. Update on the Diagnosis and Management of Giardia spp Infections in Dogs and Cats. Top Companion Anim Med. 25(3) (2010),155-162, doi.org/10.1053/j.tcam.2010.07.003

[20] Traub. RJ, Inpankaew. T, Reid. SA, Sutthikornchai. C, Sukthana. Y, Robertson. ID, et al. Transmission cycles of Giardia duodenalis in dogs and humans in Temple communities in Bangkok-A critical evaluation of its prevalence using three diagnostic tests in the field in the absence of a gold standard. Acta Trop, 111(2) (2009),

doi.org/10.1016/j.actatropica.2009.03.006

125-32.

[21] Tucker. S, Greiner. E. \&Leutenegger. C. Enteropathogens identified in dogs entering a Florida animal Shelter with normal feces or diarrhea Dermatophyte real-time PCR panel clinical validation and correlation to culture. Artic J Am Vet Med Assoc. 241(3) (2012), 33843, DOI: $10.2460 /$ javma.241.3.338

[22] Upjohn. M, Cobb. C, Monger. J, Geurden. T, Claerebout. E. \& Fox. M. Prevalence, molecular typing and risk factor analysis for Giardia duodenalis infections in dogs in a central London rescue shelter. Vet Parasitol. 172(3-4) (2010), 341-6, doi.org/10.1016/j.vetpar.2010.05.010 